\title{
A PSICOGENÉTICA WALLONIANA E O DESENVOLVIMENTO DA LINGUAGEM: IMPLICAÇÕES À EDUCAÇÃO
}

WALLONIAN PSYCHOGENETIC AND LANGUAGE DEVELOPMENT: implications for education

\section{PSICOGENÉTICA WALLONIANA Y DESARROLLO DEL LENGUAJE: implica- ciones para la educación}

\author{
Marilete Geralda da Silva-Perdigão \\ Doutora em Educação Brasileira pela Universidade Federal do Ceará (2007). \\ Universidade Federal do Maranhão-UFMA \\ marilete.geralda@ig.com.br
}

\begin{abstract}
RESUMO: O objetivo deste trabalho foi captar, na obra de Henri Wallon, o desenvolvimento da linguagem e as implicações da compreensão deste desenvolvimento para a educação das crianças em geral e daquelas com $\mathrm{Ne}$ cessidades Educativas Especiais. Assim, percorremos, especificamente, A Evolução Psicológica da Criança, obra de 1941, por ser considerado um livro que sintetiza o pensamento deste teórico. Portanto, construímos um artigo de revisão a partir da releitura da obra citada, enfocando: os fatores do desenvolvimento, localizando a linguagem neste processo; a relação entre o ato motor e a linguagem; e a relação entre esta função e o conhecimento. Para concluir, apresentamos algumas considerações, são elas: a linguagem origina-se no ato motor, e posteriormente, exerce sobre ele o seu controle; esta função estabelece uma relação de reciprocidade com o pensamento, servindo de suporte aos seus progressos e ao mesmo tempo estruturando-o; ter compreensão sobre o desenvolvimento da linguagem, juntamente com a compreensão de outros fatores, contribui tanto para o entendimento de um desenvolvimento psicológico normal dos sujeitos, como dos seus retrocessos e desvios.
\end{abstract}

PALAVRAS-CHAVE: Linguagem. Desenvolvimento. Pensamento.

ABSTRACT: The objective of this study was to capture, in the work of Henri Wallon, language development and understanding the implications of this development for the education of children in general and those with special educational needs. So we read the book The Psychological Development of the Child, a work of 1941 considered a book that synthesizes the thought of this author. Therefore, we constructed a review article of the reading of the cited work, focusing on: the factors of development, locating the language in this process; the relationship between the motor act and the language; and the relationship between this function and knowledge. To conclude, we present some considerations: language originates in the motor act and, subsequently exerts its control over it; this function establishes a reciprocal relationship with the thought and aim to support their progress, and the same time structuring it; have understanding of language development, along with the understanding of other factors, contributes to the understanding of normal psychological development of individuals, as their setbacks and detours.

KEYWORDS: Language. Development. Thought.

RESUMEN: El objetivo de este estudio fue el de capturar, en la obra de Henri Wallon, el desarrollo del lenguaje y la comprensión de las implicaciones de este desarrollo para la educación de los niños en general y aquellos con necesidades educativas especiales. Así, que hemos utilizado, específicamente, El Desarrollo Psicológico del Niño, una obra de 1941, considerado como un libro que sintetiza el pensamiento de esta teoría. Por lo tanto, hemos construido un artículo de revisión de la relectura de la obra citada, centrándose en: los factores del desarrollo, la localización de la lenguaje en este proceso; la relación entre el acto motor y el lenguaje ; y la relación entre esta función y el conocimiento. Para concluir, se presentan algunas consideraciones, que son: el lenguaje se origina en el acto motor, y, posteriormente, ejerce su control sobre él; Esta función establece una relación recíproca con el pensamiento y el objetivo de apoyar su progreso mientras su estructuración; tener conocimiento del desarrollo del lenguaje, así como la comprensión de otros factores, contribuye a la comprensión del desarrollo psicológico normal de los individuos y sus retrocesos y desvíos.

PALABRAS CLAVE: Lenguaje. Desarrollo. Pensamiento.

Artigo recebido em setembro de 2014

Aprovado em novembro de 2014 


\section{1 | INTRODUÇÃO}

$\mathrm{Na}$ teoria psicogenética do desenvolvimento psicológico de Wallon, a linguagem tem o seu lugar de destaque. É considerada por este teórico como instrumento e suporte do pensamento, estabelecendo com ele uma relação de reciprocidade.

Objetivando captar, em que momentos da teoria de Wallon, a ênfase no desenvolvimento da linguagem se faz presente, percorremos "A Evolução Psicológica da Criança", de 1941, que segundo Galvão (1998, p. 126), "É um livro de síntese que apresenta, de forma condensada, os aspectos centrais da psicogenética walloniana".

A partir do percurso apontado acima, objetivamos, também, apontar implicações para a educação das crianças em geral e, também, das crianças com Necessidades Educacionais Especiais (NEE) ${ }^{1}$, a partir da compreensão walloniana do desenvolvimento da linguagem.

Em relação à metodologia, este trabalho constitui-se como um artigo de revisão da obra citada de Henri Wallon, portanto, realizamos uma pesquisa bibliográfica sobre o desenvolvimento da linguagem a partir de uma das mais importantes obras deste autor, para construirmos este ensaio. Assim, fizemos uma "garimpagem" dos momentos que Wallon teoriza sobre o desenvolvimento desta função, já que o tema linguagem não é tratado em separado em nenhuma de suas obras, mas comparece de maneira especial, quando ele trata do desenvolvimento psicológico das crianças.

O empreendimento de esforços para compreendermos o desenvolvimento da linguagem é impulsionado pelo desejo de saber sobre a principal característica que nos funda como seres humanos e como sujeitos de cultura. Um saber que interessa sobremaneira àqueles que estão envolvidos com o processo educativo de crianças, adolescentes, jovens e adultos das mais diferentes idades, tenham eles NEE ou não. É importante destacar que este ensaio é fruto do percurso de uma pesquisadora que estuda temas e objetos relacionados à Educação Especial ${ }^{2}$ e a Educação Infantili .

O presente trabalho, a princípio, discorre sobre os fatores do desenvolvimento apontados por este autor, localizando a linguagem neste processo; discorre, em continuidade, sobre a relação existente entre $o$ ato motor $e$ a linguagem e, posteriormente, entre o conhecimento. Ao longo da apresentação do pensamento deste teórico francês, vamos apontando as implicações da sua teorização para a educação das crianças.

O esforço, para a construção deste trabalho, foi no sentido de "garimpar" na obra citada o pensamento do autor sobre a linguagem, como dissemos anteriormente, por isso pedimos desculpas antecipadas ao leitor, se o número de citações diretas de Wallon parecer-lhe excessivo. Sabemos que a discussão deste teórico sobre a linguagem não se encerra somente nesta obra, porém, a partir deste início, esforços futuros poderão ser despendidos, para melhor compreendermos o lugar da linguagem na teoria walloniana.

Com este ensaio, esperamos contribuir para uma maior compreensão e divulgação dos escritos wallonianos sobre a linguagem, para que novos saberes e fazeres sejam construídos, colaborando assim, para a educação das crianças.

\footnotetext{
${ }^{1}$ Crianças ou jovens que apresentam: deficiências sensoriais e físicas, transtornos do desenvolvimento, superdotação e/ou altas habilidades ou ainda dificuldades específicas de aprendizagem (BRASIL, 1994).

${ }^{2}$ Modalidade de ensino que transversaliza todos os níveis, etapas e outras modalidades de ensino, proporciona o Atendimento Educacional Especializado (AEE) e ainda disponibiliza recursos e serviços, orientando quanto a sua utilização no processo ensino-aprendizagem nas turmas regulares (BRASIL, 2008).

${ }^{3}$ Primeira etapa da Educação Básica destinada às crianças de zero a cinco anos, que acontece em creches e préescolas dos sistemas públicos e privados de ensino.
} 


\section{2 | O DESENVOLVIMENTO E A LINGUAGEM: FATORES}

Wallon concebe o desenvolvimento psíquico da criança de maneira dinâmica, por estágios que formam uma unidade e que seguem uma ordem necessária ao seu surgimento. Cada um deles apresenta características próprias e prepara o surgimento do seguinte, porém este surgimento não é linear, pois comporta retrocessos e crises. Além disso, as dimensões afetiva, motora e cognitiva estão em constante comunicação. Nesses momentos, fatores orgânicos e sociais interagem de forma recíproca ao longo deste processo, ou seja, "na criança, opõem-se e implicam-se mutuamente fatores de origem biológica e social" (WALLON, 1981, p. 49).

Ao longo do desenvolvimento, as mudanças que acontecem são dependentes das possibilidades da criança, das condições externas e do amadurecimento do organismo. Assim, Wallon (1981, p. 49-50) descreve a dialética entre os aspectos orgânicos e sociais:

Ao mesmo tempo que, em cada etapa, se realiza um equilíbrio estável entre as possibilidades atuais e as condições de vida correspondentes, tendem também a operarse mudanças cuja causa é estranha a exata relação funcional. Esta causa é orgânica [...]. No desenvolvimento do indivíduo, a função desperta com o crescimento do órgão e o órgão precede-a muitas vezes de longe.

Tendo em vista esta concepção interacionista do desenvolvimento humano, podemos concluir que a educação tanto das crianças consideradas normais, como das crianças com NEE se abre às possibilidades do contexto sociocultural, no qual o processo educativo acontece. Desta forma, mesmo aqueles sujeitos com um funcionamento orgânico ou psíquico diferente dos demais não estão constituídos a partir deste funcionamento, senão como resultado da interação entre aspectos orgânicos e sociais.

Wallon (1981), ao discutir sobre as relações entre a maturação do organismo e o processo de aprendizagem que estão implicadas no despertar de uma função, aponta o que chamou de atos naturais (procurar alimento, andar, agarrar, falar) como dependentes de estimulação e circunstâncias apropriadas, mas com eficácia altamente dependente da maturação das suas condições biológicas. Estes atos, diz ele, por sua determinação orgânica, são adquiridos de forma constante pelo indivíduo normal e que vive num meio que favorece minimamente o seu aparecimento. As aquisições chamadas atividades mais artificiais, segundo Wallon (1981, p. 59), dependem com maior peso da aprendizagem. Entre estas aquisições, podemos incluir a linguagem:

\footnotetext{
Quando a aquisição diz respeito a atividades mais artificiais, quer dizer, que só em circunstâncias excepcionais aparecem ao longo do desenvolvimento, a importância da aprendizagem torna-se essencial, embora não sejam menos necessárias condições funcionais adequadas. É, aliás, uma lei geral que os efeitos, dos quais nem a forma, nem o grau, nem a cronologia podem ser sensivelmente modificados pelo exercício, são reações primitivas, reações que pertencem ao equipamento psicobiológico da espécie e cuja condição dominante é a maturação funcional. Pelo contrário, o que o exercício pode desenvolver ou diversificar depende de atividades combinadas em que se traduzem os dons individuais de adaptação, iniciativa e invenção.
}

Conceber a linguagem como uma das aquisições artificiais, ou seja, que depende do exercício e da estimulação traz implicações diretas para a educação das crianças em geral e, principalmente, daquelas que apresentam dificuldade de ascensão à função simbólica, de construção de uma linguagem, como as crianças autistas, por exemplo. Cientes de que esta função não comparece 


\title{
A PSICOGENÉTICA WALLONIANA | Marilete Geralda da Silva-Perdigão
}

ao nascimento senão como possibilidade, os educadores da escola e de outros espaços poderão valorizar e proporcionar atividades interativas com seus pares e com sujeitos mais experientes do seu contexto, para que a linguagem seja estimulada e mediada.

Wallon (1981) ressalta que a aprendizagem, para a espécie humana, tem uma importância decisiva para a sua sobrevivência e desenvolvimento, pois, no início da sua vida, a criança permanece mais tempo que os filhotes de outros animais sem possibilidades de satisfazer as suas necessidades mais elementares. Isto, segundo ele, se deve à riqueza e ao inacabamento do equipamento psicobiológico que esta criança traz ao nascer:

\footnotetext{
Existe, assim, uma relação inversa entre a riqueza do equipamento e o acabamento de suas partes. Quanto maior é o número das possibilidades, maior é a sua indeterminação e maior é a margem dos progressos. Uma função que não tem que procurar a sua fórmula não sabe igualmente adaptar-se a diversas circunstâncias. (WALLON, 1981, p. 60)
}

O indivíduo da espécie humana, portanto, nasce prematuro, fato normal em várias espécies de mamífero (no canguru, por exemplo). Nestes animais, a elevação do nível evolutivo da espécie está relacionada com o aumento da sua precocidade. Por causa desta precocidade, a criança permanece um longo tempo sem que, por si só, possa satisfazer as suas necessidades, senão através das pessoas que lhe dispensam cuidados. As suas reações são os primeiros instrumentos de que dispõe para interagir com os outros, tornando-se a base para as relações interindividuais e antecipando à linguagem. Assim, esclarece Wallon (1981, p. 60-61) sobre este início de vida da criança:

\begin{abstract}
O seu único instrumento vai portanto ser o que põe em relação com aqueles que a rodeiam, isto é, as suas próprias reações que suscitam nos outros comportamentos proveitosos para ela e as reações dos outros que anunciam estes comportamentos ou comportamentos contrários. Desde as primeiras semanas e desde os primeiros dias, constituem-se encadeamentos, donde surgirão as bases das relações interindividuais. As funções de expressão precedem de longe as de realização. Antecipando a linguagem propriamente dita, são elas que primeiramente marcam o homem, animal essencialmente social.
\end{abstract}

Desta maneira, as reações motoras das crianças precisam ser logo significadas pelos seus educadores, para que o percurso de construção da linguagem prossiga. Esta é mais uma das implicações da teoria walloniana para a educação dos pequenos, inclusive daqueles que apresentam NEE: a atividade motora deve ser compreendida, respeitada e estimulada, pois é através do movimento que as crianças comunicam suas emoções e estados afetivos. $O$ movimento possibilita a relação com o mundo e com o outro. A criança, quando se movimenta, tem a chance de estabelecer uma relação afetivo-comunicativa, pois a sua primeira forma de linguagem é através do ato motor.

\section{3 | $O$ ATO MOTOR E A LINGUAGEM}

$\mathrm{O}$ ato motor ou movimento, segundo Wallon, pertence a um dos domínios funcionais que perpassam os estágios de desenvolvimento da criança. Os outros são o da afetividade, o do conhecimento e o da pessoa. Para ele, o movimento é um dos principais meios de que o homem dispõe para atuar sobre o ambiente.

O movimento pode ser um ato motor propriamente dito, quando pertence ao meio ambiente concreto. Mas ele pode tender também para fins que não se realizam ou lançar mão de meios que 


\section{A PSICOGENÉTICA WALLONIANA | Marilete Geralda da Silva-Perdigão}

não dependam de circunstâncias concretas ou da motricidade do sujeito. Neste caso, "torna-se então técnico ou simbólico e refere-se ao plano da representação e do conhecimento". (WALLON, 1981, p. 155-156) Esta passagem, diz Wallon, parece só acontecer no homem e provoca uma diferença que ele chamou de brusca entre a espécie humana e os outros animais.

Esta passagem só parece produzir-se na espécie humana. Quando se produz na criança, provoca uma brusca diferença entre as suas aptidões e as dos animais mais próximos do homem. O próprio movimento apresenta uma dupla progressão: uma respeitante à sua agilidade, frequentemente notável no animal; a outra relativa ao nível da ação que o utiliza.

(WALLON, 1981, p. 156)

O movimento tem seu início ainda na vida intrauterina. Por volta do quarto mês de gravidez, os movimentos do feto já podem ser sentidos pela mãe. Após o nascimento, a criança apresenta gestos e atitudes em respostas a determinados estímulos do meio. Os atos impulsivos, cujas motivações são mínimas, pertencem a um nível mais baixo de movimento. São descargas motoras ou vocais resultantes de autoativação e do débil controle do comportamento pela criança.

Segundo Wallon (1981), as primeiras motivações ao movimento parecem originar-se de efeitos sensoriais que começam a ser percebidos pela criança. Isto acontece, por exemplo, quando começa a perceber a sua mão e os movimentos que podem ser executados com ela.

Este ajustamento preciso do gesto ao seu efeito instaura entre o movimento e as impressões exteriores, entre as sensibilidades proprioceptivas e exteroceptivas, sistemas de relações que as diferenciam e opõem na mesma medida em que as combinam em série minuciosamente unidas. (WALLON, 1981, p. 167)

O autor fala das consequências deste ajustamento: a primeira é que as atividades do aparelho motor não mais estarão separadas do aparelho sensorial, e a segunda, é a associação do olho e da mão para a exploração do ambiente.

A compreensão de que o ajustamento do gesto ao seu efeito se constitui como indício de desenvolvimento traz consequências importantes para estimulação e educação dos bebês, seja na instituição de Educação Infantil ou na família. O educador percebendo a presença ou ausência deste indício poderá oportunizar às crianças situações do próprio cotidiano destas instituições que favoreçam a conquista da relação causa e efeito dos seus gestos, pois estas situações favorecerão um maior incremento ao desenvolvimento linguístico.

O teórico francês diz que o exemplo mais evidente de consequência desse ajustamento é o das séries auditivas e vocais da criança, prenúncio da linguagem:

Mas o exemplo mais evidente é sem dúvida o das séries auditivas e vocais que a criancinha passa longos momentos a constituir com os seus gorjeios. O som que produziu mais ou menos fortuitamente é repetido, afinado, modificado e acaba por se desenvolver em longas séries de fonemas em que as leis e as alegrias do ouvido se vão reconhecendo cada vez mais na formação dos sons. [...] a riqueza deste material fonético corresponderia ao material de todas as línguas faladas e ultrapassá-lo-ia indubitavelmente [...]. (WALLON, 1981, p. 168)

Este exercício torna a criança apta a discriminar as diferenças dos elementos fonéticos que constituirão mais tarde as palavras e serve-lhe de motivação quando passa a entender o seu significado: "Assim, o que procedia em primeiro lugar do movimento dá os primeiros resultados na percepção”. (WALLON, 1981, p. 168) Desta maneira, a aquisição da linguagem tem a sua origem 


\section{A PSICOGENÉTICA WALLONIANA | Marilete Geralda da Silva-Perdigão}

no ato motor, especificamente, quando este se ajusta ao aparelho sensorial.

O educador conhecedor deste ajuste e atento fará com que um man man pronunciado ocasionalmente pelo bebê, inserido no contexto da língua portuguesa, ganhe o significado de mamãe. Esta mediação auxiliará a criança a estabelecer a relação entre significados (imagens, ideias) e significantes (palavras, gestos, sons emitidos) e, consequentemente, formar os seus primeiros signos linguísticos.

Wallon (1981) acrescenta que as atividades sensóriomotora da criança desenvolvem-se no espaço que será explorado e conhecido por ela, porém estas atividades acontecem a partir de objetivos ocasionais. Ao longo desta exploração, não tardam a surgir aquelas que estabelecem objetivos confrontando-os com os seus meios: são as atividades de imitação. Elas surgem pelo poder de atração precoce e poderoso que a criança sente pelas pessoas que a rodeiam:

Os primeiros objetivos, perseguidos por si próprios, que regulam exteriormente a atividade da criança, são os modelos que ela imita. Esta é uma fonte inesgotável de iniciações, que a fazem exceder, muitas vezes, aliás, de um modo completamente formal, o quadro das ocupações a que as suas necessidades a podem incitar diretamente. (WALLON, 1981, p. 171)

Mas, Wallon faz uma alerta: a criança só imita as pessoas ou ações que lhe são atraentes, porque na base das atividades imitativas está a afetividade (amor, admiração, rivalidade). A criança, quando imita, não faz uma reprodução imediata ou literal do que observou. Entre a observação e a imitação, enfatiza o autor, normalmente ocorre um intervalo que chamou de incubação, pois segundo este teórico, "à sua percepção vem juntar-se uma plasticidade interna, que não é ainda mais que vigilância motora, ou postura, e de que o movimento efetivo não poderá sair sem elaboração". (WALLON, 1981, p. 174) Localiza a aquisição da linguagem como uma das consequências desta função imitativa:

A aquisição da linguagem, por exemplo, não é senão um longo ajustamento imitativo de movimentos e séries de movimentos ao modelo que, há já muitos dias, permite à criança compreender qualquer coisa dos propósitos dos que a rodeiam. Este modelo pode mesmo atrasar-se em relação às impressões auditivas do momento. (WALLON, 1981, p. 175)

Portanto, a imitação é uma conduta representativa que revela o esforço do sujeito em se implicar no processo, o que evidencia que tal conduta seja o resultado de um comportamento inteligente. A construção da linguagem é resultado de um processo imitativo e isto requer que os educadores oportunizem esta imitação às crianças, para que se tornem sujeitos de linguagem.

Outro ato da criança que revela o indício de representação e, consequentemente, da aquisição da linguagem é o simulacro, o que quer dizer, segundo Wallon, um ato sem objeto real. Requerem este tipo de ato os jogos simbólicos, as brincadeiras de faz de conta. Galvão (1998, p. 73) exemplifica estas atividades:

Por exemplo, a criança que arruma os braços como se estivesse carregando uma boneca e balança-o como se estivesse ninando. Ou a criança que faz o gesto de pegar o sabão, de abrir a torneira, de esfregar e de enxugar, como se estivesse dando banho em seu bichinho de estimação. Nessas situações, o movimento é capaz de tornar presente o objeto e substituí-lo. Esses gestos simbólicos, chamados de simulacro, estão na origem da representação. Com o fortalecimento das funções intelectuais (do processo ideativo), reduz-se o papel do movimento na atividade cognitiva. 


\section{A PSICOGENÉTICA WALLONIANA | Marilete Geralda da Silva-Perdigão}

Segundo Wallon, o simulacro pode contribuir para levar as imagens e as ideias para o plano mental onde se podem formular relações mais gerais e menos subjetivas e individuais entre as ações e entre os objetos. Ao longo do desenvolvimento, portanto "o gesto, aliás, ultrapassa a si mesmo para terminar no signo". (WALLON, 1981, p. 182) Este autor cita os sons que compõem as palavras como exemplo desta ultrapassagem:

Os próprios sons de que se compõe a palavra não são uma simples sucessão; pertencem a conjuntos que juntam à sucessão pura a previsão simultânea e mais ou menos ampla das palavras ou elementos fonéticos a enunciar, da sua posição recíproca, da sua exata distribuição. (WALLON, 1981, p. 183).

O ato motor, portanto, para Wallon, não está limitado somente ao mundo dos objetos e das ações concretas, mas se torna uma base indispensável para o pensamento, através dos seus meios de expressão. Ato motor e pensamento se influenciam reciprocamente. $\mathrm{O}$ ato motor se encontra na base da representação, do pensamento.

\subsection{Disciplinas mentais e linguagem}

Ao longo do seu desenvolvimento, a motricidade exterior da criança sofre uma redução e ela vai se tornando capaz de ajustar os seus movimentos ao mundo físico. Este progresso é possibilitado pela capacidade que a criança vai adquirindo de ter controle voluntário sobre o ato motor. A esta capacidade, Wallon deu o nome de disciplinas mentais. Ela é resultado do amadurecimento de áreas do córtex cerebral responsáveis pela inibição e discriminação e da aprendizagem. Wallon (1981, p. 93) situa o aparecimento desta capacidade por volta dos 6/7 anos, quando "é possível subtrair a criança às suas ocupações espontâneas para fazer com que se entregue a outras."

A princípio, a criança, ao atuar em seu ambiente, mostra-se ora perseverante ora instável em suas ações, à deriva das necessidades exteriores ou do controle exclusivo das circunstâncias do momento. Wallon (1981, p. 96), diz que a diminuição desta perseverança e instabilidade ocorre juntamente com o início da capacidade de abstração:

[...] caminham lado a lado a diminuição concomitante da perseverança e da instabilidade, a aptidão para prosseguir durante mais tempo uma mesma atividade, a menor dependência em relação ao atual e ao concreto, o emprego de símbolos que abrem acesso a um pensamento com maior capacidade de abstração.

Os instrumentos simbólicos e as palavras não definem o pensamento, mas são, a partir de Wallon, suportes e substitutos que ajudam a opor a intenção do momento ao ato mental, confrontar impressões de objetos que não estão presentes e é, por isso, que há concomitância dos progressos da representação simbólica com a diminuição da perseverança e instabilidade da criança e a sua dependência às situações concretas.

Os instrumentos simbólicos, particularmente a linguagem, segundo Wallon, modificam as reações das crianças aos estímulos, servindo de intermediário entre estas e as motivações ad vindas do meio. A linguagem acrescenta ou substitui relações menos pessoais, mais objetivas e possíveis de serem evocadas.

[...] a estas relações ainda concretas, que subordinam estreitamente a ação às circunstâncias vividas, é contudo indispensável que a linguagem venha acrescentar ou substituir relações menos pessoais, mais objetivas, mais livremente evocáveis. As orientações que 


\section{A PSICOGENÉTICA WALLONIANA | Marilete Geralda da Silva-Perdigão}

oferece à ação são as únicas que a tornam capaz de se harmonizar com os enquadramentos cronológicos de elaboração social, e de premeditar, de realizar sincronismos ou sucessões que não sejam simplesmente dadas e impostas pelo curso das coisas. (WALLON, 1981, p. 111)

A linguagem, também, é causa (coadjuvante) do aparecimento do que Wallon designou como poder de constelação que se traduz na capacidade de agrupar as posições que levam a um objeto ou que permitam apanhá-lo, é o poder de percorrer cada uma dessas posições, sem se perder do conjunto e nem do objetivo. Esta capacidade se apoia nas unidades sensoriomotoras. Ela varia, de acordo com Wallon, com a espécie, com a raça, com os indivíduos e com o treino e aprendizagem.

Com a linguagem, o comportamento da criança progride. Seus atos ordenam-se e combinam-se para o alcance de determinados objetivos, porque se torna capaz de evocar circunstâncias passadas e de raciocinar através de imagens ou palavras e de discursos interiores.

Wallon esclarece que a capacidade que a criança adquire em distribuir de forma ordenada suas ações se torna possível devido a certas disposições psíquicas e estas disposições tornam, também, possível a linguagem. Esta, a princípio, como efeito, logo se transforma em fator de tal capacidade. E acrescenta:

É aliás muito frequente que na evolução mental a causalidade se transfira assim, ou se divida, ou se torne recíproca. Em particular, como demonstraram as disciplinas mentais, há um entrelaçamento perpétuo entre as condições de substrato orgânico e as condições de substrato social. (WALLON, 1981, p. 115)

Dependente tanto de aspectos orgânicos quanto sociais, o desenvolvimento da capacidade de abstração que resulta em disciplinas mentais pode ocorrer sem grandes percalços para a maioria das crianças, mas quando se trata de desenvolvimento humano, há que se considerar a ocorrência de retrocessos, crises e conflitos, como afirma Wallon. Mesmo que a criança não apresente alguma necessidade educacional especial, há possibilidade de ela apresentar dificuldades neste percurso. Como exemplo, podemos citar a criança que em tenra idade é rotulada como hiperativa na escola e em outros contextos socioeducativos. Os educadores precisam compreender que esta criança deve ser auxiliada a significar os seus movimentos e inquietude, colaborando desta forma, para que aconteça o desenvolvimento da linguagem e do discurso interno que possa guiar os seus atos, pois uma das finalidades da educação é tornar os sujeitos capazes de substituírem os atos por palavras. Esta substituição possibilita a constituição de sujeitos de linguagem e, consequentemente, pensantes e reflexivos.

Podemos ilustrar o surgimento desta linguagem interna, no relato da mãe de uma criança de seis anos e três meses:

Pérola da Mabel de hoje (Vou contar exatamente como ela disse): "Mamãe, todos os cérebros, exceto o meu, não falam?" ou seja, "É só o meu cérebro que fala?" Eu respondo: "Não, filha, todo cérebro 'fala'. Isto que você ouve são as suas ideias e os seus pensamentos". E ela responde: "Mas como eu faço para o meu cérebro parar de falar? Ele não para de falar! Tem muitas ideias lá! Como é que cabe? Eu acho que meu cérebro vai explodir, porque tem muitas e muitas ideias lá dentro!" (Lídia).

Este é o momento de uma grande descoberta feita pela criança: o pensar sobre o pensar. O início do discurso interno evidencia a principal característica que nos distingue dos outros animais, 
pois nos possibilita, dentre outras funções psicológicas, a criação, o planejamento e o pensar antes de agir. Porém, vale ressaltar que o surgimento deste discurso é, necessariamente, precedido e resultado de relações intersubjetivas que acontecem no contexto socioeducativo dos sujeitos.

\title{
4 | A RELAÇÃO ENTRE O CONHECIMENTO E A LINGUAGEM
}

Wallon aponta que há uma coincidência entre os princípios da fala na criança com o progresso das suas capacidades práticas. Esta coincidência pode ser verificada quando estudiosos compararam o comportamento do indivíduo humano com o do macaco. (BUHLER, 1930; KOHLER, 1925) Antes do uso da palavra, o bebê humano e o macaco têm comportamentos parecidos, mas a partir do uso da palavra, estes comportamentos se diferenciam. Neste início, a linguagem apresenta-se como uma aptidão para imaginar objetos, deslocações, trajetórias e direções invisíveis. Uma aptidão que também possibilita ordenar as sucessivas partes do discurso.

A partir desta relação que a linguagem estabelece com o pensamento, Wallon (1981, p. 186) enfatiza que:

\begin{abstract}
Sem falar aqui das relações sociais que torna possíveis e que a modelaram, nem o que cada dialeto contém e transmite de história, é a linguagem que fez mudar-se em conhecimento a mistura estreitamente combinada de coisas e de ação em que se resolve a experiência bruta. Ela não é, verdade se diga, a causa do pensamento, mas é o instrumento e o suporte indispensáveis aos seus progressos. Se há por vezes um atraso num ou noutro, a sua ação recíproca restabelece rapidamente o equilíbrio.
\end{abstract}

A linguagem permite ao objeto do pensamento se deslocar da concretude, permite a representação das coisas, reintegra o ausente no presente e permite exprimir, fixar e analisar o presente. Os signos são os pontos de referência que a linguagem sobrepõe aos momentos da experiência vivida. Eles permitem ao pensamento seguir "livres trajetórias, unir o que estava desunido, separar o que tinha sido simultâneo" (WALLON, 1981, p. 187).

Wallon diz que o avanço que a linguagem permite ao pensamento e o esforço que dele exige podem ser evidenciados pelo atraso que ele sofre, se ela tende a desaparecer. Ele cita, como exemplo, a dificuldade dos afásicos de classificar objetos, a partir de seus evidentes atributos. Está presente também na forma de classificação de algumas crianças com paralisia cerebral. Estes sujeitos realizam tal atividade classificando estes objetos a partir de critérios subjetivos ou de critérios que se relacionam ao seu ego.

Esta maneira do afásico fazer relações entre os objetos, diz Wallon, é também encontrada no processo de evolução do sujeito normal: é o egocentrismo que se encontra também na linguagem. Assim, diz Wallon (1981, p. 188):

Também neste aspecto se impõe a comparação com a criança, em quem se observam semelhantes disparidades no emprego ou na compreensão das palavras segundo a situação, e que sabe dissociar mal de si mesma o curso dos acontecimentos ou a realidade das coisas, agrupar mal os objetos, se não existirem as relações que a sua própria atividade neles possa introduzir.

A criança, a princípio, também não tem noção do "antes" e do "depois", pois vive no agora, sem focar os acontecimentos, sem ter o recurso da imagem para recordar e sem fazer previsões. Pois, integrar os termos "amanhã", "hoje" e "ontem" (presente, passado e futuro) simultaneamente, através da linguagem, exige dela um modo de funcionamento que ainda não possui. Os seus relatos são encenações que incluem os gestos, preponderando o aparelho motor sobre o aparelho 


\title{
A PSICOGENÉTICA WALLONIANA | Marilete Geralda da Silva-Perdigão
}

conceptual e esta preponderância se torna necessária para dar força à formação e a manutenção da idéia, segundo Wallon (1981, p. 189):

\begin{abstract}
Exercendo-se os mecanismos de ação antes do da reflexão, quando a criança se quer representar uma situação, não o conseguirá se não se comprometer primeiro nela, de qualquer modo, pelos seus gestos. O gesto precede a palavra e depois é acompanhado por ela antes de a acompanhar, para enfim se reabsorver mais ou menos nela.
\end{abstract}

Wallon esclarece que este tipo de manifestação da linguagem evidenciando o colamento do pensamento ao objeto se traduz por uma viscosidade mental. Esta forma de funcionamento impede a utilização dos signos e pontos de referência verbais que dispensam o pensamento sobre os objetos e ações. É o resultado da indiferenciação entre o plano dos objetos e ações e o plano das ideias.

O pensamento da criança também apresenta uma característica que se manifesta na sua linguagem. É o que ele chamou de sincretismo. Por causa desta característica, ela percebe os fatos e situações de maneira justaposta e sem ainda perceber relações lógicas entre eles, perdendo-se muitas vezes em detalhes, evidenciando uma forma de pensar mais singular que global.

A característica sincrética do pensamento da criança também traz manifestações peculiares da linguagem. Wallon, para descrever este tipo de pensamento, compara-o ao pensamento do adulto, o qual atua por análise e síntese, ou seja: denominando, enumerando e decompondo os objetos e situações e recompondo-os. Na criança, a percepção das coisas ou das situações, diz Wallon (1981, p. 193-194):

[...] continua a ser global [...], isto é, o pormenor permanece indistinto. No entanto, a atenção da criança parece-nos muitas vezes incidir sobre o pormenor das coisas. [...] No entanto, não é como pormenores dum conjunto que ela os apreende, e é por isso que Ihes é tão sensível. Subordinados ao conjunto, imediatamente perderia o interesse por eles, quer porque deixaria de atingir o seu significado próprio quer porque os consideraria demasiado acessórios. [...] A percepção da criança é, portanto, mais singular que global; dirige-se a unidades sucessivas e mutuamente independentes, ou que não têm entre si outros laços para além da sua própria enumeração.

Como manifestação deste sincretismo, a linguagem da criança traduz-se em uma adaptação ainda não imediata ao objeto, as frases são construídas a partir de uma palavra ou sílaba repetida, são optativas ou imperativas e os sentidos são circunstanciais e são mais a tradução do entusiasmo e da afetividade da criança, do que das características do objeto.

Pelo fato de se apegar a pormenores e detalhes das situações, na sua conduta e nos seus relatos, os aspectos fortuitos podem substituir o essencial, pois ainda não sabe distinguir aspectos subjetivos dos objetivos. Não sabe diferenciar-se das situações nas quais se envolve e dos objetos que deseja. Esta confusão é transferida para a sua maneira de representar e de se expressar através das palavras. "Por ela, o objeto temido torna-se maléfico, mesmo sem contato físico; o desejo considera-se eficaz, mesmo sem intervenção material”. (WALLON, 1981, p. 196) Esta crença mágica (que não tem nada de mágico), diz Wallon, é somente resultado da indiferenciação entre os planos mentais e motores, entre o mundo interior (ego) e o mundo exterior.

Para ele, esta indiferenciação que a criança faz entre ela e o outro resulta em uma insuficiente indistinção entre os outros que se evidencia na sua linguagem:

Quando a criança pequena chama 'papá' a todo homem que vê, seria igualmente prematuro dizer que os identifica com o seu pai ou que os inclui numa categoria designada pelo 


\section{A PSICOGENÉTICA WALLONIANA | Marilete Geralda da Silva-Perdigão}

nome de uma única pessoa, por ignorar o nome coletivo. Ela sofre a reação de conjunto, junto, motivada por alguns de seus traços, em que as partes se confundem com o todo e são, conseqüentemente, suscetíveis de provocar a confusão mútua de conjunto, de outro modo diferentes. (WALLON, 1981, p. 195-196).

Outra característica do pensamento da criança e que se evidencia na sua linguagem é que ele pode ser considerado do tipo narrativo, mas com sérias reservas, diz Wallon. A relação que estabelece entre as coisas e as situações restringe-se somente nas sucessões das imagens ou na sucessão dos relatos. As palavras preferidas "depois", "então" e "quando" são usadas de maneira fortuita, de acordo com os seus desejos e inspirações do momento, sem formar unidades ou porções de sentido. Isto se deve, segundo o autor, ao manejo imperfeito da noção de causalidade entre os fatos, pela criança.

Sobre a noção de causalidade, diz Wallon, só será conhecida por uma primeira dissociação entre o ego e o outro, o exterior. Assim, Wallon (1981, p. 212) ainda esclarece:

[...] as questões de causalidade: 'porque?', só surgem várias semanas depois das questões de local e de simpatia, que são quase simultâneas. Com efeito, a distinção local entre ela e outrem é indispensável para que a participação se possa transformar em simples simpatia. E sem que haja uma ultrapassagem do momento presente, não há anterioridade nem sobrevivência imagináveis da causa para os seus efeitos.

Portanto, a diferenciação entre o eu e o outro e a ultrapassagem do momento presente são condições para que a criança adquira a noção de causalidade, que se evidencia, entre outros momentos, na sua sintaxe, quando esta narra ou explica as suas experiências. E o primeiro desenho desta noção está relacionado com as ligações que ela tem com as pessoas, pois elas são fonte de ações e são intermediárias entre a criança e os objetos que ela deseja. O seu progresso da noção de causalidade, segundo Wallon, está ligado ao desenvolvimento da função de categorizar, de classificar os objetos, que aponta para o avanço das funções intelectivas e se aproxima do modo de pensar do adulto.

A relação da linguagem com o conhecimento, a partir de Wallon, nos faz compreender o jeito próprio de comunicação das crianças pequenas para expressarem o pensamento. Os educadores, principalmente, os da primeira infância precisam dar a devida importância à relação afetiva, que é estabelecida com o outro para os avanços da linguagem e do pensamento dos pequenos. As crianças se constituem como sujeitos falantes (usando uma língua ou gestos, como no caso das crianças surdas), capazes de agir sobre o mundo, evoluindo de um pensamento sincrético e egocêntrico ao pensamento analítico-sintético, categorial e lógico, quando estabelece esta relação com os seus pares e com os mais experientes.

Portanto, quer no contexto familiar, na escola e/ou em outros contextos, a Educação Infantil seja das crianças consideradas normais, seja das crianças consideradas com NEE, deverá ter como eixo principal as interações entre os sujeitos, que sejam promotoras de avanços da sua linguagem e pensamento. Estas interações devem acontecer entre as crianças com as mais diferentes características e necessidades e entre elas e os educadores. Estes devendo posicionarem-se como guias-interlocutores-intérpretes das narrativas construídas e comunicadas através dos seus gestos e palavras por aquelas. 
A PSICOGENÉTICA WALLONIANA | Marilete Geralda da Silva-Perdigão

\section{5 | CONSIDERAÇÕES FINAIS}

A partir deste percurso, por alguns pontos da teoria walloniana sobre a evolução psicológica da criança, enfocando particularmente a linguagem, podemos fazer algumas considerações. A primeira delas é que, no transcurso do desenvolvimento desta função, a sua aquisição é considerada por Wallon como atividade artificial em oposição ao que chamou de atos naturais. Ela é assim designada pela importância que tem a aprendizagem para o seu aparecimento. A origem da linguagem está no ato motor e as funções de expressão são a sua antecipação, assim como o simulacro dá indícios do seu aparecimento. No início, gestos que se repetem tornam-se signos, elementos usados pela criança para se referir a objetos e situações.

A criança desenvolve a linguagem imitando as pessoas com as quais se sente atraída e o seu início coincide com os progressos das atividades práticas desta criança. A princípio, a linguagem revela a principal característica do seu pensamento infantil: o sincretismo. Nos seus relatos, o acessório toma lugar do essencial e o uso dos termos "quando", "então" e "depois" são fortuitos pelo seu manejo imperfeito da noção de causalidade, que, por sua vez é consequência da indiferenciação que a criança faz entre o seu ego e o outro.

Originando-se no ato motor, e posteriormente, exercendo sobre ele o seu controle, a linguagem, estabelece uma relação de reciprocidade com o pensamento: serve de suporte aos seus progressos e ao mesmo tempo o estrutura.

Cientes de como se dá o desenvolvimento da linguagem, principalmente, da sua origem, educadores infantis e também de outros níveis de ensino poderão estar atentos à importância do afeto e do movimento nas atividades com as crianças. Este conhecimento Ihes permitem perceber o significado, na evolução psicológica dos educandos, do desenvolvimento da função linguística para o controle motor e os progressos da função intelectiva. Ter esta compreensão contribuiria, juntamente com a compreensão de outros fatores, tanto para o entendimento de um desenvolvimento considerado normal dos sujeitos, como das suas peculiaridades, dos seus retrocessos e desvios, dando-lhes condições de fazerem intervenções e mediações, para que o desenvolvimento tanto da criança normal como da que tenha alguma necessidade especial tenha o seu prosseguimento. 
A PSICOGENÉTICA WALLONIANA | Marilete Geralda da Silva-Perdigão

\section{Referências}

BRASIL. DECLARAÇÃO DE SALAMANCA: sobre princípios, políticas e práticas na área das necessidades educativas especiais. Brasília, DF, Corde, 1994 Disponível em: <portal.mec.gov.br/seesp/arquivos/pdf/ salamanca.pdf>. Acesso em: 25 mar. 2014.

Ministério da Educação. Secretaria de Educação Especial. Política Nacional de Educação Especial na Perspectiva da Educação Inclusiva. Brasília, DF, 2008.

BUHLER, K. The mental development of the child. New York: Harcourt; Brace, 1930.
GALVÃO, Izabel. Henri Wallon: uma concepção dialética do desenvolvimento infantil. Petrópolis: Vozes, 1998.

KOHLER, W. The mentality of apes. New York: Harcourt; Brace, 1925.

WALLON, Henri. A evolução psicológica da criança. Lisboa: Edições 70, 1981. 